\title{
Clinical and electrophysiological study of the pattern of conduction times in the distribution of the sciatic nerve
}

\author{
M. M. GASSEL AND W. TROJABORG \\ From the Department of Clinical Neurophysiology, University Hospital, Copenhagen, Denmark
}

This study defines the normal range of motor conduction velocities and distal latencies in nerves to various leg and foot muscles, and in the proximal and distal segments of the same nerve to the foot muscles. The significance of differences in temperature in individual variations in nerve conduction velocity has been evaluated.

A series of patients with various diseases of the sciatic nerve or its branches has been similarly investigated. The pattern of abnormality in nerve conduction has been found to be of considerable assistance in clinical evaluation.

\section{METHODS AND MATERIAL}

The sciatic nerve was stimulated proximally in the buttock or upper thigh in its position either between the greater trochanter of the femur and the tuberosity of the ischium, or directly below the middle of this position on a line drawn downwards to the apex of the popliteal fossa. The lower position of stimulation of the sciatic nerve was in the apex of the popliteal fossa at the level of the upper border of the femoral condyles. At the ankle the posterior tibial nerve was stimulated posterior to the middle part of the medial malleolus, and the anterior tibial nerve at a line joining the upper part of the malleoli. The conduction velocity was determined between the points of stimulation, and the latency of response from the distal stimulating point. Action potentials were recorded intramuscularly from the tibialis anticus, gastrocnemius, and soleus in the leg, and from the extensor digitorum brevis and abductor hallucis in the foot.

The stimulating electrode at all positions, other than the proximal stimulating point in the thigh, was a bipolar surface electrode with a diameter of $6 \mathrm{~mm}$. for each electrode and a centre-to-centre separation of $25 \mathrm{~mm}$. (DISA 13K62). The surface of the skin was prepared by gentle abrasion and rubbing with ether. Needle electrodes were used for the stimulation in the upper thigh or buttock. The needles were $0.4 \mathrm{~mm}$. in diameter and $8 \mathrm{~cm}$. in length, stainless steel and non-insulated. The needles were placed $2.5 \mathrm{~cm}$. apart, at a depth of 3 to $6 \mathrm{~cm}$., in the same position as that of the bipolar surface stimulating electrode. A thin flat lead plate, ground $3 \times 8 \mathrm{~cm}$., was placed between the stimulating and recording electrodes. The stimulus was a rectangular pulse of $0.7 \mathrm{msec}$. duration. It was obtained from a stimulator (DISA) with a double shielded output transformer (Buchthal, Guld, and Rosenfalck, 1955). The output impedance was $15 \mathrm{k} \Omega$ and the maximum output current $15 \mathrm{~mA}$. The stimulating current was $2 \mathrm{~mA}$ at threshold and 4 to $6 \mathrm{~mA}$ with supramaximal stimulation, both with surface and with needle electrodes; this current was obtained with 10 and $25 \mathrm{~V}$ between the electrodes. A $50 \mu \mathrm{sec}$. signal was introduced to indicate the onset of the stimulus. The recording electrodes were three concentric needles with an external diameter of $0.45 \mathrm{~mm}$.; the leading-off area of the core was $0.07 \mathrm{~mm}^{2}$ (DISA 13K 50).

In five subjects an electrode convertible from bipolarity to unipolarity was used in recording from the gastrocnemius and soleus muscles. The bipolar electrodes consisted of a cannula (external diameter $0.65 \mathrm{~mm}$.) containing two insulated wires each with a non-insulated tip of $0.03 \mathrm{~mm} .{ }^{2}$, $0.5 \mathrm{~mm}$. apart. Simultaneous recordings from the three electrodes placed in the abductor hallucis, extensor digitorum brevis, and tibialis anticus were amplified and displayed on the three independent cathode ray tubes of the electromyograph (DISA). The time base was $1 \mathrm{msec}$. per $\mathrm{mm}$.; a time base of 2 or $5 \mathrm{msec}$. per $\mathrm{mm}$. was also used in cases with pronounced slowing in nerve conduction.

The stimulus strength at threshold for a motor response was first determined and then a maximal response obtained using a stimulus strength which was at least twice that of the threshold stimulus. The amplification was adjusted to visualize the entire action potential complex. Five to 10 photographic recordings were made of the maximal motor response at one given polarity of the stimulus pulses; then the polarity of the pulse was reversed and the procedure repeated. The latency was measured from the stimulus artifact to the start of the action potential. The values obtained with the bipolar stimulating electrode at opposite polarity of stimulus pulses were averaged in calculating the final value. Conduction velocity was determined by dividing the distance between the proximal and distal stimulating points by the difference in latency of the action potential recorded on stimulation at these points.

There was no regular or significant difference in the latency of the response in a comparison of stimulation by 
surface and needle electrodes in the popliteal space in five normal subjects.

The distance between the centre of the bipolar stimulating electrode at each level of stimulation and the recording electrodes was measured with a tape measure.

The intramuscular temperature was measured 4,3 , and $2 \mathrm{~cm}$. in depth in the mid-posterior thigh, mid-calf, and mid-anterior crural muscle mass. A needle, $0.7 \mathrm{~mm}$. in diameter, $50 \mathrm{~mm}$. in length with a thermocouple at its point (Ellab Type $\mathbf{K}_{8}$ ), and a galvanometric thermometer (Ellab Type $\mathrm{TE}_{3}$ ) was used.

The temperature of the room in which the test was performed was $21-23^{\circ} \mathrm{C}$.

The procedure was well tolerated, and there were no untoward complications.

\section{MATERIAL}

Twenty-four normal subjects examined ranged in age from 19 to 67 years; nine subjects were over 50 years of age and five under 21 years of age. Thirteen patients were investigated; in most instances the patients had wasting or weakness of some muscles in the distribution of the sciatic nerve which resulted from a localized lesion in nine, polyneuritis in two, and Charcot-Marie-Tooth disease in two.

\section{RESULTS IN NORMAL SUBJECTS}

The range of normal values for the conduction velocity and distal latency is presented in Table I.

There is no significant difference between the conduction velocities in the nerves to the muscles of the leg, viz., tibialis anticus, soleus and gastrocnemius; and no difference in the nerves to the muscles of the foot, viz., extensor digitorum brevis and abductor hallucis. However, there is a 20 to $22 \%$ higher conduction velocity in the nerves to the prox mal muscles than to the distal muscles of the lowe extremity $(P<0.001)$. There is a $11 \%$ higher conduc $=$ tion velocity in the proximal segment than in the distal segment of the nerves to the foot muscle $(P<0.01)$. The nerves to the muscles of the leg have a 12 to $17 \%$ higher conduction velocity than the proximal segments of the nerves to the foot muscles $(\mathrm{P}<0.05$ to $<0.01)$.

INTRAMUSCULAR TEMPERATURE AND MOTOR NERV CONDUCTION VELOCITY The intramuscular tempera ture gradient in depth in the mid-thigh, mid-calf, an mid-anterior crural compartment is indicated if Table II. The temperature values in these three regions were generally of similar order in any given subject. The mean temperature of the mid position ( $3 \mathrm{~cm}$. in depth) differed little from the average of th values of the three determinations in depth. InFig. 1a the conduction velocity in the segment of nerve in the thigh and leg is charted in relation to the average of the temperature values in the mid-thigh and mid-leg respectively. A linear regression analysis of the values plotted in Fig. 1 showed a change of $1.9 \pm 0.7 \mathrm{~m}$./sec. per degree Centigrade for the leg atid $1 \cdot 7 \pm 1 \cdot 1 \mathrm{~m} . / \mathrm{sec}$. per degree Centigrade for the thigh:

\section{RESULTS IN PATIENTS}

TWO PATIENTS WITH POLYNEURITIS In a patient WgT recurrent polyneuritis (EMG 8592) with absent? deep tendon reflexes but no muscular weakness wasting the conduction velocity in the entire tribution of the sciatic nerve was much slowed and

TABLE I

NORMAL RANGE OF MOTOR CONDUCTION VELOCITY AND DISTAL LATENCY OF THE SCIATIC NERVE

\begin{tabular}{|c|c|c|c|c|c|c|c|c|c|c|c|c|c|}
\hline \multirow{3}{*}{$\begin{array}{l}\text { Evoked Muscle } \\
\text { Action Potential } \\
\text { Recorded from: }\end{array}$} & \multicolumn{9}{|c|}{ Conduction Velocity } & \multicolumn{4}{|c|}{ Latency from Distal Stimulating Point } \\
\hline & \multicolumn{3}{|c|}{$\begin{array}{l}\text { Buttock-Ankle } \\
(61-87 \mathrm{~cm} .)\end{array}$} & \multicolumn{3}{|c|}{$\begin{array}{l}\text { Buttock-Popliteal Fossa } \\
(23-42 \mathrm{~cm} .)\end{array}$} & \multicolumn{3}{|c|}{$\begin{array}{l}\text { Popliteal Fossa-Ankle } \\
(35-47 \mathrm{~cm} .)\end{array}$} & \multirow[t]{2}{*}{$N$} & \multirow[t]{2}{*}{ Mean (m./sec.) } & \multirow[t]{2}{*}{ S.D. } & \multirow[t]{2}{*}{ Distance $(\mathrm{cm}$} \\
\hline & $N$ & Mean $(m . / s e c)$. & $S . D$. & $N$ & Mean (m./sec.) & S.D. & $N$ & Mean (m./sec.) & S.D. & & & & \\
\hline $\begin{array}{l}\text { Abductor hallucis } \\
\text { Extensor digitorum }\end{array}$ & 20 & $48 \pm 0 \cdot 8$ & $3 \cdot 5$ & 20 & $51 \pm 1 \cdot 3$ & $5 \cdot 8$ & 21 & $46 \pm 0 \cdot 8$ & $4 \cdot 6$ & 23 & $6.8 \pm 0.2$ & 0.9 & $11-15$ \\
\hline $\begin{array}{l}\text { brevis } \\
\text { Tibialis anticus } \\
\text { Soleus } \\
\text { Gastrocnemius }\end{array}$ & 17 & $49 \pm 1 \cdot 2$ & $4 \cdot 1$ & $\begin{array}{l}18 \\
15 \\
20 \\
19\end{array}$ & $\begin{array}{l}51 \pm 1 \cdot 6 \\
55 \pm 1 \cdot 2 \\
56 \pm 1 \cdot 2 \\
56 \pm 1 \cdot 3\end{array}$ & $\begin{array}{l}7 \cdot 0 \\
4 \cdot 5 \\
5 \cdot 5 \\
5 \cdot 6\end{array}$ & 17 & $46 \pm 1 \cdot 1$ & $4 \cdot 3$ & $\begin{array}{l}17 \\
15 \\
21 \\
21\end{array}$ & $\begin{array}{l}6 \cdot 2 \pm 0 \cdot 2 \\
5 \cdot 4 \pm 0 \cdot 2 \\
5 \cdot 4 \pm 0 \cdot 2 \\
5 \cdot 5 \pm 0 \cdot 2\end{array}$ & $\begin{array}{l}0 \cdot 8 \\
0 \cdot 7 \\
0 \cdot 8 \\
0 \cdot 7\end{array}$ & $\begin{array}{r}9-13 \\
13-17 \\
13-17 \\
13-17\end{array}$ \\
\hline
\end{tabular}

TABLE II

Temperature $\left({ }^{\circ} \mathrm{C}.\right)$ measured at

INTRAMUSCULAR TEMPERATURE GRADIENT IN DEPTH

\begin{tabular}{|c|c|c|c|c|c|c|c|}
\hline \multirow[t]{2}{*}{1 emperature ( ${ }^{\circ}$.) measured at } & \multirow[t]{2}{*}{$N$} & \multicolumn{2}{|l|}{$4 \mathrm{~cm}$. Depth } & \multicolumn{2}{|l|}{$3 \mathrm{~cm}$. Depth } & \multicolumn{2}{|l|}{$2 \mathrm{~cm}$. Depth } \\
\hline & & Mean & S.D. & Mean & S.D. & Mean & $S . D$ \\
\hline $\begin{array}{l}\text { Mid-thigh } \\
\text { Mid-calf } \\
\text { Mid-anterior crural }\end{array}$ & $\begin{array}{l}17 \\
17 \\
17\end{array}$ & $\begin{array}{l}36.6 \pm 0.6 \\
35.8 \pm 0.2 \\
36.0 \pm 0.2\end{array}$ & $\begin{array}{l}0.2 \\
0.9 \\
0.8\end{array}$ & $\begin{array}{l}36.3 \pm 0.2 \\
35.4 \pm 0.3 \\
35.6 \pm 0.2\end{array}$ & $\begin{array}{l}0.8 \\
1 \cdot 1 \\
0.8\end{array}$ & $\begin{array}{l}35.5 \pm 0.3 \\
34.6 \pm 0.3 \\
35.2 \pm 0.3\end{array}$ & $\begin{array}{c}1.0 \\
1.0 \\
1.0\end{array}$ \\
\hline
\end{tabular}



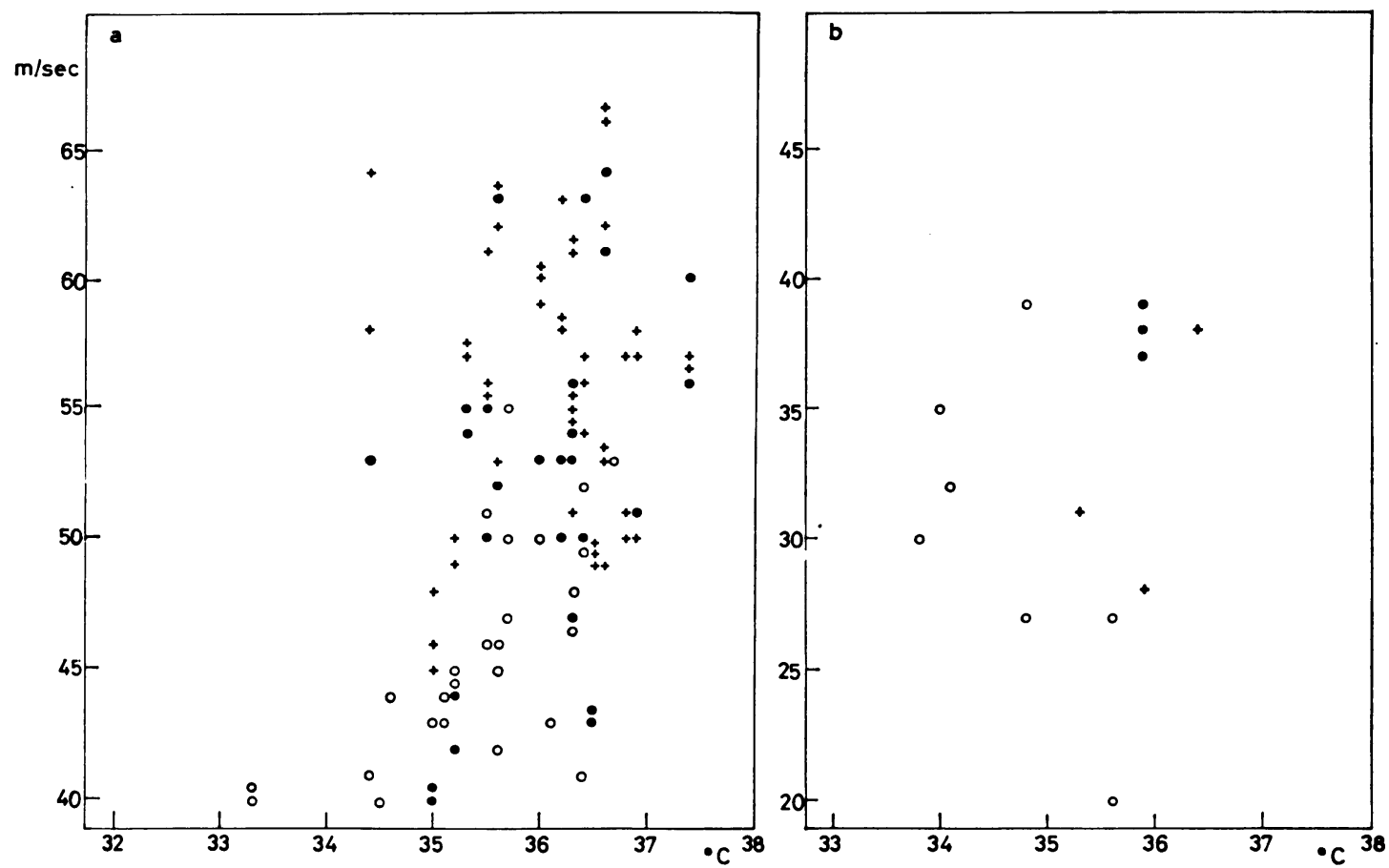

FIG. 1a

FIG. 1b

FIG. 1. Relation of motor conduction velocities in the segment of nerve in the thigh and leg to the mean intramuscular temperature in the respective areas: (a) in normal subjects and (b) in patients with reduced motor nerve conduction velocity. Cross denotes conduction velocity to a proximal muscle (soleus, gastrocnemius, or tibialis anticus). Closed circle denotes conduction velocity in the proximal segment and open circle that in the distal segment of the nerve to a distal muscle (abductor hallucis or extensor digitorum brevis).

all latencies were greatly prolonged. The conduction velocity to the foot muscles was 20 to $24 \mathrm{~m}$./sec.; there was greater slowing peripherally with a velocity of 18 to $19 \mathrm{~m} . / \mathrm{sec}$. in the distal segment and a latency of 30 to $33 \mathrm{msec}$, while the velocity in the proximal segment was $32 \mathrm{~m}$./sec. The conduction velocity to the muscles of the leg was much slowed, e.g., 27 $\mathrm{m}$./sec. to the anterior tibial muscle and a latency of $20 \mathrm{msec}$.

A patient with diabetic polyneuritis (EMG 8789) had diffuse wasting of the muscles of the lower limbs, most marked peripherally. There was a conduction velocity of $30 \mathrm{~m}$./ $/ \mathrm{sec}$. to the abductor hallucis and no difference between proximal and distal segments; the latency at the ankle was $10 \mathrm{msec}$. No response was obtained in the atrophic extensor digitorum brevis. Less pronounced slowing in conduction velocity was found to the leg muscles with the velocity ranging from 42 to $44 \mathrm{~m}$./ $/ \mathrm{sec}$. and the latency from 6.5 to $8 \mathrm{msec}$.

TWO PATIENTS WITH CHARCOT-MARIE-TOOTH DISEASE Both had diffuse wasting of muscles of the lower extremities, most marked peripherally (EMG 8799 and 8882). There was no response in the atrophic extensor digitorum brevis in either patient. The conduction velocity to the abductor hallucis ranged from 25 to $33 \mathrm{~m}$./sec., with no difference in proximal and distal segments, and the latency at the ankle was 9 to $14 \mathrm{msec}$. The velocity to the muscles of the leg ranged from 23 to $39 \mathrm{~m}$./ $/ \mathrm{sec}$. and the latency from 8 to $10 \mathrm{msec}$.

NINE PATIENTS WITH A TRAUMATIC LESION OF THE SCIATIC NERVE OR ITS BRANCHES Seven patients with a lesion of the common peroneal nerve in the region of the knee and two patients with a lesion of the sciatic nerve were examined. Six of the cases presented a problem in differential diagnosis.

Lesion of the common peroneal nerve in the region of the knee A 28-year-old man (EMG 8767) had diffuse and marked wasting and weakness of the lower extremities and buttocks subsequent to acute poliomyelitis six years previously. He was referred for examination because of progressive difficulty in walking over the last two years. The patient was unable to walk unaided, and there was a 
slow and laboured stepping gait with the aid of hand crutches.

Deep tendon reflexes were absent, and there was no sensory loss. Some recordings from the investigation are shown in Figure 2. The evoked potentials from the tibialis anticus and extensor digitorum brevis are polyphasic on stimulation of the left sciatic and popliteal nerves. The conduction velocity is normal in the nerve to the tibialis anticus and in the proximal segment of the nerve to the extensor digitorum brevis. There is no change in the degree of the polyphasia on stimulation of the upper thigh and popliteal regions in either muscle, whereas there is less polyphasia of the potential in the extensor digitorum brevis on stimulation at the ankle. The conduction velocity in the distal segment of the nerve to the extensor digitorum brevis was $27 \mathrm{~m}$./sec. and that in the proximal segment $50 \mathrm{msec}$. The conduction velocity to the abductor hallucis, soleus, and gastrocnemius was normal, 50 to $56 \mathrm{~m}$. $/ \mathrm{sec}$., and the shape of the evoked potentials were normal. The same results were found on the right side. The peroneal muscles were found to be similarly affected.

These findings indicate that the deterioration in this patient with poliomyelitis was due to a bilateral lesion of the common peroneal nerve in the vicinity of the capitulum fibulae. A similar spectrum of results was found in three other patients: one with familial spastic paraplegia; a second with a traumatic neuroma of the common peroneal nerve at the capitulum fibulae; and another with foot drop of six months' duration.

A patient with foot drop of 23 days' duration (EMG
8773) was found to have a neurapraxia of the commone peroneal nerve. There was no reaction in the extenso $\bar{Z}$ digitorum brevis and a much reduced voltage of the potential in the tibialis anticus on stimulation of the sciatico and popliteal nerves; however, a normal potential was evoked in both muscles on stimulation below the capitū lum fibulae, and the conduction velocity in the distalo segment of the nerve to the extensor digitorum brevis was normal. Normal potentials were found at all levels of stimulation in the abductor hallucis, soleus, and gastroc nemius.

A patient developed a left foot drop after a surgicat. repair and traction of the knee in treatment of a fracture? dislocation of the acetabulum of the femur (EMG 8788) Stimulation of the sciatic and popliteal nerves evoked $\frac{\bar{\alpha}}{2}$ markedly polyphasic potential in the tibialis anticus and $\overline{\bar{n}}$. potential of low amplitude in the extensor digitorun brevis. The potential recorded in the extensor digitorun? brevis and an early component of that in the tibialis anos terior was absent on stimulation of the common peroneat nerve at the capitulum fibulae (Fig. 3) demonstrating that these potentials were derived from the muscles innervate by the posterior tibial nerve. The conduction velocity in the nerve to the tibialis anticus muscle was normal. There were normal evoked potentials and a normal conduction velocity in the nerves to the abductor hallucis, soleus, and gastrocnemius. The findings suggest a lesion of the common peroneal nerve at the knee rather than at the hip.

The investigation contributed little to the evaluation of another patient with fracture dislocation of the tabulum and a history of foot drop noticed two weeks

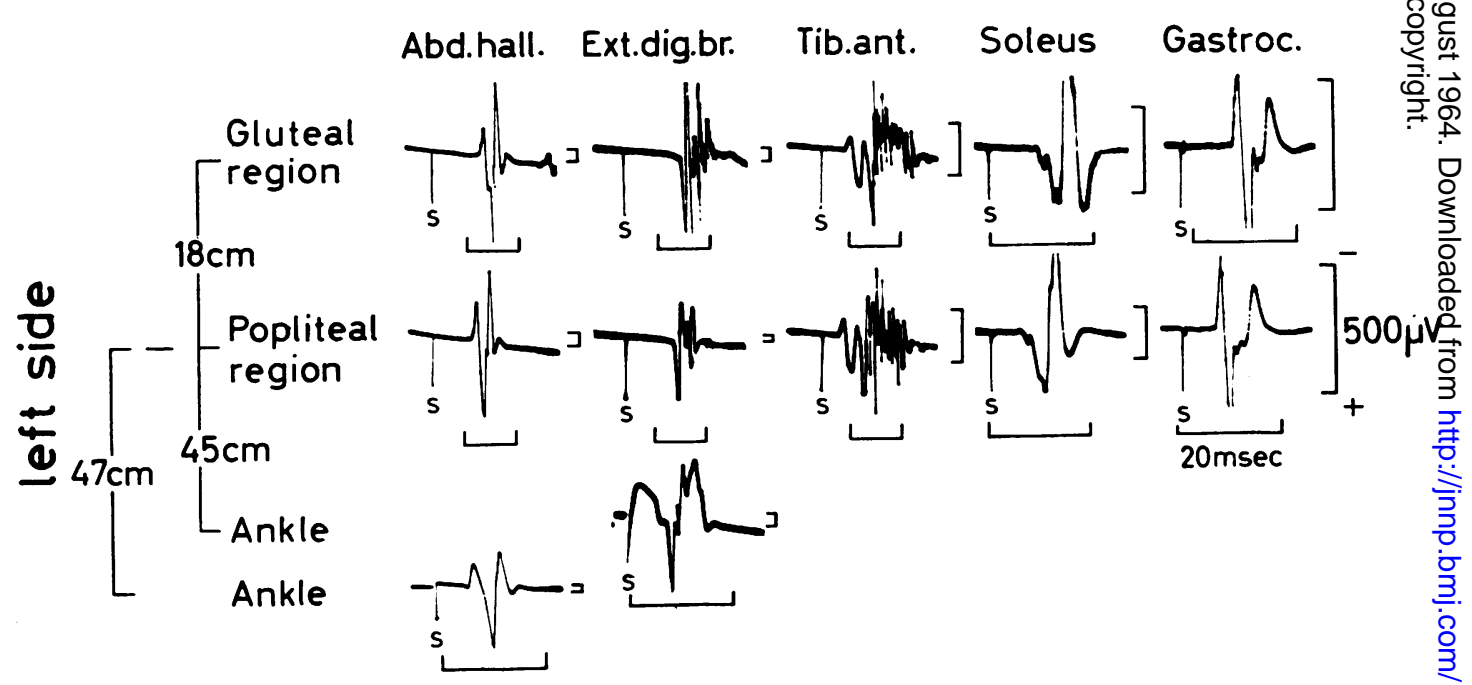

FIG. 2. Evoked potentials in a patient with a bilateral lesion of the common peroneal nerve at the capitulum fibulae Conduction velocity in the posterior tibial nerve to (1) m.abductor hallucis: $53 \mathrm{~m} . / \mathrm{sec}$. (glut.reg.-popl.reg.) and $50 \mathrm{~m} . / \mathrm{seG}$ (popl.reg.-ankle); (2) m.soleus: $56 \mathrm{~m} . / \mathrm{sec}$.; (3) m.gastrocnemius: $55 \mathrm{~m} . / \mathrm{sec}$.; Conduction velocity in the anterior tibiat nerve to (1) m.tibialis anticus: $54 \mathrm{~m}$./sec.; (2) m.extensor digitorum brevis: $50 \mathrm{~m}$./sec. (glut.reg.-popl.reg.) and $27 \mathrm{~m} . / \mathrm{sec}$ (popl. reg.-ankle). Note the polyphasia of the potentials evoked from $\mathrm{mm}$. tibialis anticus and extensor digitorum brevis of stimulation of the gluteal and popliteal regions. There is less polyphasia of the potential in the extensor digitorum brevłs on stimulation at the ankle ( $S=$ time of stimulus). 


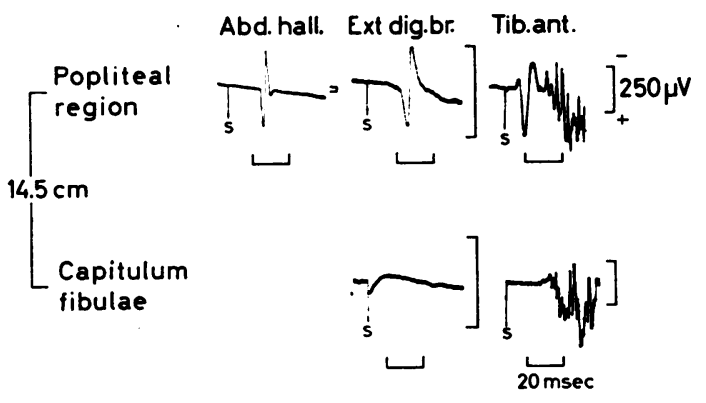

FIG. 3. Evoked potentials in a patient with a lesion of the common peroneal nerve at the capitulum fibulae. Note the absence of a response in the extensor digitorum brevis on stimulation at the capitulum fibulae (lower line), indicating that the low voltage potential recorded in this muscle and the early component of that in the tibialis anticus on stimulation of the popliteal region (upper line) were conducted potentials from muscles innervated by the posterior tibial nerve. Note also the marked increase in latency to the anterior tibial muscle (15 and $12 \mathrm{msec}$.) on stimulation at the popliteal region and capitulum fibulae respectively. ( $S=$ time of stimulus.)

after surgical repair with hip traction (EMG 8763). There was reduced amplitude of the evoked potentials recorded from the tibialis anticus and extensor digitorum brevis but the conduction velocity was normal; and the responses were normal in the muscles supplied by the tibial nerve.

Lesion of the sciatic nerve Two patients were examined with foot drop which developed shortly after injections of hypnophen (equal amounts of barbital and aprobarbital as ammonium salts) into the upper posterior thigh.

In one uncooperative psychotic patient (EMG 8762) a polyphasic potential was elicited in the tibialis anticus on stimulation at the upper thigh, and less polyphasia on stimulation in the popliteal region; the conduction velocity was reduced to $37 \mathrm{~m}$./ $/ \mathrm{sec}$. No response was obtained from the wasted extensor digitorum brevis. The responses were normal from the muscles innervated by the posterior tibial nerve. In the other patient (EMG 8579) no response was obtained from either the extensor digitorum brevis or tibialis anticus at any level of stimulation. The responses were normal in the muscles supplied by the posterior tibial nerve. There were pronounced signs of denervation in the caput brevis of the biceps femoris and a reduced amplitude potential was elicited in this muscle on stimulation of the sciatic nerve. The findings confirmed a lesion of the sciatic nerve in the upper thigh.

INTRAMUSCULAR TEMPERATURE AND MOTOR NERVE CONDUCTION VELOCITY In the small sample plotted in Fig. $1 \mathrm{~b}$ there is no significant relationship between the extent of slowing of conduction velocity and the average of the intramuscular temperatures in depth in the middle of the region which contained the pathological segment of nerve. There was a slight shift to the left in the average temperature values in the mid-calf, of the order of $1^{\circ} \mathrm{C}$. less than in normal subjects.

\section{DISCUSSION}

PATTERN OF CONDUCTION VELOCITIES IN NORMAL SUBJECTS A 20 to $22 \%$ higher conduction velocity was found in the nerve to the leg muscles than to the foot muscles. A similar difference has been found in the conduction velocity of nerves to proximal muscles of the upper and lower extremities (Redford, 1958; Fernand Gassel and Diamantopoulos, 1964). Gasser and Grundfest (1939) established in experiments on cats and rabbits that the conduction velocity of a nerve fibre was directly proportional to its diameter within the myelin sheath; and Fernand and Young (1951) demonstrated in rabbits that muscular nerves to proximal muscles contained fibres of larger diameter than those to distal muscles. This provides presumptive evidence that such a difference in diameter of fibres is the operative agent in humans.

There was no difference in conduction velocity in the nerves to the leg muscles, i.e., tibialis anterior, soleus, or gastrocnemius. The same conduction velocity to the tibialis anterior and gastrocnemius is consistent with the demonstration that the diameters of fibres in the nerves to these muscles do not show pronounced differences (Fernand and Young, 1951). However, the absence of a difference in conduction velocity in the nerves to the gastrocnemius and soleus is surprising. Hay (1901) originally demonstrated in rabbits that the nerve fibres to the soleus muscle, which is a red muscle and contracts slowly, have smaller diameters than those to the gastrocnemius which is a white muscle and is faster contracting. This observation has been repeatedly verified in small mammals (Eccles and Sherrington, 1930; Hagbarth and Wohlfart, 1952; Eccles, Eccles, and Lundberg, 1958), and the finding is believed to be a valid generalization for all white and red muscles. Although Fernand and Young (1951) found no consistent difference in the diameter of nerve fibres to red and white muscles, nevertheless they confirmed the specific difference in the diameters of nerve fibres to the soleus and gastrocnemius. A possible source of error in this investigation of conduction velocity is that because of the proximity of these muscles, a potential generated in one muscle and conducted to the electrode in the other muscle may interfere with the integrity of the recorded action potential and invalidate the calculated conduction velocity. However, the electrode was placed as superficially as possible in the gastrocnemius and deeply into the soleus; and in five instances bipolar recording electrodes were used to limit this potential source of 
error. There was no difference in the results with bipolar electrodes. Furthermore measurement of the conduction velocity using the intersection of the positive-negative deflection of the spike with the base line as reference point showed no significant difference from that calculated from the beginning of the complex.

No difference was found in the conduction velocity between the motor nerves to the extensor digitorum brevis or abductor hallucis muscles, either in the total length of the nerve tested or in the proximal or distal segments. Thomas, Sears, and Gilliatt (1959) reported a mean conduction velocity of $49.7 \mathrm{~m} . / \mathrm{sec}$. (S.D. $7 \mathrm{~m}$./sec.) in the distal segment of the nerve to the extensor digitorum brevis, and of $43.2 \mathrm{~m} . / \mathrm{sec}$. (S.D. $5 \mathrm{~m} . / \mathrm{sec}$.) in that to the abductor hallucis. Their proximal stimulation was of the anterior tibial nerve at the capitulum fibulae in the test to the extensor muscle, and of the posterior tibial nerve behind the knee in the test to the abductor hallucis. In the present study the recordings from both muscles were taken simultaneously on stimulation of the sciatic and tibial nerves. Fernand and Young (1951) reported that the spectrum of diameters of fibres in nerves to muscles at the same level of the limb do not, in general, show pronounced differences.

The conduction velocity in the proximal segments of the motor nerves to the foot muscles (extensor digitorum brevis and abductor hallucis) was $11 \%$ higher than that in the distal segments; a similar difference was also found by Arrigo, Cosi, and Savoldi (1962) and by Buchthal, Guld, and Rosenfalck (1955). Redford (1958) did not find a significantly higher mean conduction velocity in the proximal segment of the nerve to the extensor digitorum brevis in the upper part of the leg compared to that in the lower part of the leg; however, the proximal calculation was made over the short distance from the stimulating point in the midpopliteal region to that at the capitulum fibulae. The lower conduction velocity in the distal segment found in the present study is probably related to the occurrence of fibres of smaller diameter in the more peripheral parts of the motor nerves (Eccles and Sherrington, 1930). The evidence suggests that this is due both to branching and conical tapering of the fibres (Fernand and Young, 1951).

It is significant that there was much less difference between the conduction velocity in motor nerves to leg muscles and to foot muscles when calculated over the same length in the thigh; and it also suggests that the occurrence of finer fibres towards the periphery of nerves may be of relevance.

INVESTIGATION OF PATIENTS WITH NERVE LESIONS The examination demonstrated slowing of conduc- tion velocity in nerves to leg muscles as well as too foot muscles in cases with polyneuritis and Charcot- $Z$ Marie-Tooth disease; and can be of assistance in the investigation of patients with severe distal muscularo atrophy in whom no evoked potentials are presen in the foot muscles. The study of the conduction characteristics of the segment of nerve in the thigh also permits a determination of the distribution of involvement of nerves in these conditions. Thus in the patients with Charcot-Marie-Tooth disease an diabetic polyneuropathy the entire length of nerve to the foot muscles was affected to an equal degree $\stackrel{?}{?}$ whereas in the patient with recurrent polyneuritis there was a graded involvement with more pro음. nounced slowing in the periphery of the nerve and an disproportionate increase in distal latency; conduc $\frac{\mathbb{}}{2}$ tion velocity in the nerves to the muscles of the lege showed the same type of abnormality.

The pattern of involvement of the nerves was of value in the diagnosis and localization of a lesion of $\overrightarrow{\dot{\omega}}$ the sciatic nerve or its branches. A bilateral lesione of the common peroneal nerve at the capitulum fibulae was shown to be the cause of deterioration in a patient with poliomyelitis and severe generalized wasting of muscles of the lower extremity. A simitar aetiology was demonstrated for the deteriorationgin a patient with a spastic paraparesis. These patiefts are more susceptible to nerve compression and fice possibility of this complication as a cause of pe्e gression in their disability should be considered.

The examination was also shown to be of valuegin the sometimes difficult differentiation of a lesions the anterior tibial nerve in the region of the capitulariso fibulae from one in the region of the hip.

TEMPERATURE AS A FACTOR IN MOTOR NERVE CONDUCO TION VELOCITY

An explanation of the variation of conduction velocio ties from subject to subject found, alternative to that of the relationship to the spectrum of diameters of nerve fibres, is provided by the factor of temperature variations. The cryptic variable of fluctuations in temperature or a temperature gradient in the limb has been broached in explanation of variations in conduction velocity found on different examinations of the same subject, in differences between proxima $\bar{P}$ and distal parts of the same nerve or between differen nerves.

Reduction in conduction velocity with decrease in temperature was early demonstrated by Helmholt (1850) and confirmed by Gasser (1931) and Lorente de Nó (1947). However, the influence of the variable of temperature in the distribution of conduction. velocities is not easily evaluated (Lambert, 1962) N Henriksen (1956) investigated the relationship by cooling and warming the forearm in a water bath an 
relating the change in conduction velocity in the ulnar nerve to the intramuscular temperature measured with a thermistor inserted at a depth of $2 \mathrm{~cm}$. in the proximal one-third of the forearm. He found an average of 2.4 metres per second decrease in velocity per degree Centrigrade decrease in temperature; and this relationship was effective over the range of $24^{\circ}$ to $36^{\circ} \mathrm{C}$. Johnson and Olsen (1960) stated that there was a decrease in conduction velocity of $5 \%$ per degree Centigrade. Kato (1960) found that ulnar nerve conduction velocity was $5 \cdot 3$ metres per second higher when tested at a room temperature of $30^{\circ} \mathrm{C}$. than when tested at $20^{\circ} \mathrm{C}$.

In the present study the intramuscular temperature gradient in depth in the middle of the thigh, calf, and anterior crural compartment was determined under the usual laboratory conditions. It was found that there was a correlation between the conduction velocity and the intramuscular temperature corresponding to a decline of about $1.8 \mathrm{~m}$./ $/ \mathrm{sec}$. per degree Centigrade. As the variation of the temperature is small (S.D. $=0.6-1.1{ }^{\circ} \mathrm{C}$.), differences in temperature cannot explain the large individual variations in conduction velocity (S.D. $=3.5-7 \mathrm{~m} . / \mathrm{sec}$.); nor is it likely that a $0.8^{\circ} \mathrm{C}$. lower mean temperature in the mid-calf than the mid-thigh can entirely account for the $5 \mathrm{~m}$./ $/ \mathrm{sec}$. lower conduction velocity in the distal segment to the foot muscles. In the patients there was no significant relationship between the temperature gradient and the extent of reduction of conduction velocity. These results support the conclusions of Redford (1958) and Henriksen (1956 and Carpendale (1956) that in the ordinary test environment variations in temperature contribute little to variations in conduction velocity either in normal subjects or in patients with neuropathy; although in exceptional cases, especially with poliomyelitis (Henriksen, 1956; Johnson, 1962), low temperature may be of importance in the reduction of conduction velocity.

\section{SUMMARY AND CONCLUSIONS}

The pattern of motor conduction times in the distribution of the sciatic nerve and its major branches was studied in 24 normal subjects and in 13 patients with nerve lesions.

The sciatic nerve was stimulated in the gluteal region or upper thigh and in the upper popliteal region; the anterior and posterior tibial nerves were stimulated at the ankle. Recordings were made from the tibialis anticus, gastrocnemius, and soleus muscles in the leg, and from the extensor digitorum brevis and abductor hallucis muscles in the foot.

A higher mean conduction velocity was found in the nerves to the muscles of the leg than to the foot muscles. There was no difference in conduction velocity between the nerves to the individual muscles of the leg or foot. The conduction velocity in the proximal segment of the nerve to the foot muscles was $11 \%$ higher than that in the distal segment. There was a relationship between the conduction velocity and the intramuscular temperature corresponding to a change in velocity of $1.8 \mathrm{~m}$./sec. per degree Centigrade in normal subjects. However, the range of temperature encountered in normal subjects cannot account for the wide individual variations in conduction velocity. There was no significant correlation between the intramuscular temperature and the extent of reduction of conduction velocity in patients.

Reduction of conduction velocity and prolongation of distal latency in nerves to leg and foot muscles was demonstrated in patients with polyneuritis and Charcot-Marie-Tooth disease; and the diffuse or graded distribution and pattern of involvement of the nerves in these conditions was examined. The investigation was found to be of aid in diagnosis and localization of a lesion of the sciatic nerve or its branches.

\section{REFERENCES}

Arrigo, A., Cosi, V., and Savoldi, F. (1962). Electroenceph. clin. Neurophysiol., suppl. No. 22, p. 23.

Buchthal, F., Guld, C., and Rosenfalck, P. (1955). Acta physiol. scand., 34, 75.

Carpendale, M. T. F. (1956). M.S. (Phys. med.) Thesis, University of Minnesota.

Eccles, J. C., Eccles, R. M., and Lundberg, A. (1958). J. Physiol. (Lond.), 142, 275.

- , and Sherrington, C. S. (1930). Proc. roy. Soc. B, 106, 326.

Pernand, V. S. V., and Young, J. Z. (1951). Ibid., 139, 38

Gassel, M. M., and Diamantopoulos, E. (1964). Neurology (Minneap.), 14, 222.

Gasser, H. S. (1931). Amer. J. Physiol., 97, 254.

- , and Grundfest, H. (1939). Ibid., 127, 393.

Hagbarth, K. E., and Wohlfart, G. (1952). Acta. anat. (Basel), 15, 85.

Hay, J. (1901). Lpool med.-chir. J., 21, 431.

Helmholtz, H. (1850). Arch. Anat. Physiol. wissensch. Med., p. 276; reprinted in Helmholtz, H. (1883). Wissenschaftliche Abhandlungen, 1, 475. Barth, Leipzig.

Henriksen, J. D. (1956). M.S. (Phys. med.) Thesis, University of Minnesota.

Johnson, E. W. (1962). Arch. Neurol. (Chic.), 7, 365.

$\longrightarrow$, and Olsen, K. J. (1960). J. Amer. med. Ass., 172, 2030.

Kato, M. (1960). Tohoku J. exp. Med., 73, 74.

Lambert, E. H. (1962). Electroenceph. clin. Neurophysiol., suppl. No. 22, p. 9

Lorente de Nó, R. (1947). Stud. Rockefeller Inst. Med. Res., 132, 284.

Redford, J. W. B. (1958). M.S. (Phys. med.) Thesis, University of Minnesota.

Thomas, P. K., Sears, T. A., and Gilliatt, R. W. (1959). J. Neurol. Neurosurg. Psychiat., 22, 175. 